IRA-International Journal of Applied Sciences ISSN 2455-4499; Vol.04, Issue 03 (2016)

Institute of Research Advances

Pg. no. 394-406

http://research-advances.org/index.php/IRAJAS

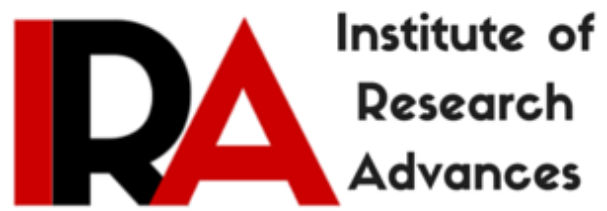

\title{
Mindfulness and Psychology Based Self-help Mobile Application: A Promising New Approach in Reducing Work Stress and Anxiety
}

\author{
Dr. Shanthi Lakshmi Duraimani \\ Uber Health Tech Pvt Ltd \\ E-1/15-1, 1st Cross, Syndicate Bank Colony \\ Off Bannerghatta Road, Arekere \\ Bangalore, Karnataka, India 560076
}

Type of Review: Peer Reviewed.

DOI: http://dx.doi.org/10.21013/jas.v4.n3.p3

\section{How to cite this paper:}

Duraimani, S. (2016). Mindfulness and Psychology Based Self-help Mobile Application: A Promising New Approach in Reducing Work Stress and Anxiety. IRAInternational Journal of Applied Sciences (ISSN 2455-4499), 4(3), 394-406. doi:http://dx.doi.org/10.21013/jas.v4.n3.p3

(C) Institute of Research Advances

\section{(cc) EY-NO}

This work is licensed under a Creative Commons Attribution-Non Commercial 4.0 International License subject to proper citation to the publication source of the work.

Disclaimer: The scholarly papers as reviewed and published by the Institute of Research Advances (IRA) are the views and opinions of their respective authors and are not the views or opinions of the IRA. The IRA disclaims of any harm or loss caused due to the published content to any party. 


\section{ABSTRACT}

Nearly one-third of the working populations in most developed countries report high or extreme levels of negative stress. Over the last decade, the escalating costs associated with workplace stress indicate an international trend among industrialized nations. Stress is considered as one of the root causes for many psychological disorders. Anxiety is one of the common disorders that can rise due to negative stress. Consulting health professionals to overcome mental health problem is time-consuming, expensive, and may affect the privacy for many people. To overcome these limitations, we are presenting a model for a self-help mobile app program that can be a powerful, cost-effective, personalized, and convenient tool to overcome mild to moderate stress and anxiety. Mindfulness Meditation is a scientifically proven and standardized technique for many mental health problems. Many professionals have developed Mindfulness-based mobile applications. However, they do not address the core root causes of the mental health problem as the conventional psychological therapy does. Therefore, the proposed self-help mobile app merges mainstream psychological process and mindfulness in reducing minor to moderate stress, and anxiety.

Keywords: Mindfulness Meditation, work stress, anxiety, mental health, mobile app, work productivity.

\section{Introduction}

Stress is increasingly becoming accepted as a workplace phenomenon negatively affecting a growing number of people across the world. The National Institute for Occupational Safety and Health (1999) defined stress as: 'The harmful physical and emotional responses that occur when the requirements of the job do not match the capabilities, resources, needs of the workers.' [1]

Nearly one-third of the working populations in most developed countries report high or extreme levels of stress. Over the last decade, the escalating costs associated with workplace stress indicate an international trend among industrialized nations. A study of mental health policies and programs for workers in Finland, Germany, Poland, United Kingdom and United States shows an increasing incidence of mental health problems, with almost one in ten workers subjected to stress, depression, anxiety or burnout, leading to consequences of unemployment and hospitalization. In most countries, the overall cost of work-related accidents and diseases, including stress-related ones, is still very high. For example, in the European Union, it is estimated at 2.6 to $3.8 \%$ of the gross domestic product (GDP). The reasons for this trend include information overload, intensification of work and time pressure, high demands for mobility and flexibility, being constantly "on call" due to mobile phone technology, and last but not least the worry of losing one's job. [2]

Some people who are stressed may show relatively mild outward signs of anxiety, such as fidgeting, biting their fingernails, tapping their feet, etc. In other people, chronic activation of stress hormones can contribute to severe feelings of anxiety (e.g., racing heartbeat, nausea, sweaty palms, etc.), feelings of helplessness and a sense of impending doom. Thought patterns that lead to stress (and depression, as described above) can also leave people vulnerable to intense anxiety feelings. [3]

The literature suggests that provision of training and support for employees can impact positively on stress and anxiety levels. Programs, which provide training and education lead to innovations which bring about changes in work organization. A survey carried out to assess the impact of psychological training programs on health care professionals stress found that trained nurses reported positive changes in their stress and anxiety levels $[4,5]$. There are many de-stress programs have been found and seem to benefit the workers. Mindfulness meditation is one of the profound techniques scientifically proven to reduce 
stress and other psychological problems. Mindfulness is a standardized meditation program created in 1979 by Jon Kabat-Zinn from the effort to adapt Buddhist mindfulness meditation. Mindfulness is a state of mind in which one focuses on experience in the present moment in a non-judgmental way. [6] Originally, it was developed as a group based program for patients with chronic pain. [7, 8] In the past two decades, it has been proposed as a treatment for many diseases, showing a good efficacy for many mental and physical disorders. [9-11]

\section{Mindfulness Meditation Research}

Mindfulness meditation consists of developing focused attention, nonjudgmental awareness, openness, curiosity, and acceptance of internal and external present experiences, all of which aim to help individuals act more reflectively rather than impulsively. [12] Practice of mindfulness meditation results in a decreased response to stress and anxiety. [13-15]

Neuroscience and psychological research suggest that the intentional practice of mindfulness increases gray matter in the brain involved in memory processes, emotional regulation, empathy, and perspective taking. More importantly, it reduces the bias towards negative thoughts. Adam Luke and Brian Gibson of Central Michigan University looked at how instructing white college students in mindfulness would affect their "implicit bias" or unconscious negative reactions to black faces and faces of older people. After listening to a 10-minute mindfulness audiotape, students were significantly less likely to pair implicitly negative descriptive words with black and old faces than were those in a control group. [16] From a neuroscientific perspective, a study from Harvard Medical School found that there was a significant cortical thickness increase in the right insula and the somatosensory cortex of Mindfulness-based Stress Reduction (MBSR) trainers, coupled with a significant reduction of several psychological indices related to worry, state anxiety, depression, and alexithymia. [17]

Another study aims to determine whether an online mindfulness program, created for the Dow Chemical Company, could cut stress while enhancing the resiliency and well-being of employees. Eighty-nine participants completed scientific scales designed to measure their degree of stress, mindfulness, resilience, and vigor. The subjects are divided into two groups, one to take the online class and one to sit on the waiting list. After the first group had finished, the researchers came six months later to see how everyone was doing. They found that the group that took the class was less stressed, more resilient, and more energetic than the group that couldn't yet take the class. 'This online mindfulness intervention seems to be both practical and useful in enhancing overall employee well-being.' [18] In fact, a recent meta-analysis also found that web-based psychotherapeutic interventions using cognitive behavioral therapy (CBT) or psycho-education achieved similar benefits to those of traditional in-person therapy. [19]

Allexandre and his colleagues conducted a study to determine the effectiveness of an 8-week web-based mindfulness stress management program (WSM) in a corporate call center and added the benefit of group support. One hundred sixty-one participants were randomized to WSM, WSM with group support, WSM with group and expert clinical support, or wait-list control. Perceived stress, burnout, emotional and psychological well-being, mindfulness, and productivity were measured at baseline, week 8 and week 16, and one year. All active groups demonstrated significant reductions in perceived stress and increase in emotional and psychological well-being compared with control group. [20]

Traditionally, stress management programs, including those based on mindfulness, have been taught by a trained instructor or counselor in a group or one-on-one sessions. For employers, this in-person format may be costly and difficult to arrange around employee work schedules; thus, in-person formats may result in an inability to engage a large proportion of employees and may limit the program's impact. [21] 
Online programs may provide an efficient and affordable alternatives, but it will be limited to computerbased employees.

In recent times, apps are an integral part of our daily micro-moments, with people spending an average of 30 hours per month with them. [22] From internet to email, they offer on the go access to information never before possible. Various features of smartphones make them a powerful tool to deliver self-help program. First, as portable devices that are highly valued by individuals, they tend to be switched on and remain with the owner throughout the day. Second, smartphones are cheaper and convenient. Therefore, the self-help mobile app program may be an alternative delivery medium that could improve personal well-being, reduce work stress, reduce anxiety, improve relationships in the workplace, and increase job satisfaction.

\section{Need for Self-help Program}

The self-help programs that are available through Universities, mental health centers, or on the internet, are focusing on one of the traditional psychotherapies. Moreover, many mindfulness meditation apps are claiming to reduce mental health problem. However, many of them fail to fulfill the need of the people. For instance, recently a study conducted in the Department of Social and Welfare Studies, Linköping University, Sweden on the effectiveness of Internet-based Cognitive Behavioral Therapy (ICBT) in reducing the symptoms of depression among heart failure. The study was conducted for 9-weeks and they did not find significant statistical differences in the effectiveness of reducing depression compared to the control group. [23] The possible reasons could be that ICBT is not helping the users to understand the therapy, does not offer peer support, CBT alone does not provide complete therapeutic effect to solve the problem. Therefore, one or more promising therapies can be incorporated to address any mental health problem.

To overcome these limitations, and to develop an alternative approach to traditional stress and anxiety management programs, we designed a self-help mobile app program titled "awaremeditationapp.com" to improve the quality and accessibility of mental health treatment for people who suffer from work stress and anxiety. In this article, we will discuss the self-help program that merges the psychological process with mindfulness in reducing stress and anxiety.

\section{Aware Self-help App Model}

Although genetic influences undoubtedly play a role in developing cognitive behaviors and personality, environmental influences as well play a significant role. Specifically, bad upbringing, traumatic experience, less nurturing and social support might lead to minor to moderate stress and anxiety. Depending on the severity of the environmental influences, it can also result in chronic disorder. Bad genetic and environmental factors build a new neural circuit for negative thought processing and increasing the negative thinking of any events or situations. The more negative thinking manifest, more new neural circuit begin to develop. Eventually, they lay down a strong pathway in the brain for negative thinking processing. Negative thinking process will lead to three critical components called stress, fear, and anxiety. All the three components are interlinked to each other. For instance, fear can act as a precursor for the manifestation of stress and anxiety. Stress can serve as a precursor for the expression of anxiety and fear. Thereby, anxiety can affect the physical, mental, and emotional well-being. Aware selfhelp app model was carefully designed by understanding the root causes and physical, mental, and emotional manifestation of stress and anxiety (figure $1 \& 2$ ).

\section{Visual Analog Scale}


Single-item Visual Analog Scales (VASs) have been used in psychological assessment since the early $20^{\text {th }}$ century and have subsequently been employed successfully in the assessment of a wide variety of health-related constructs including pain [24-26], quality-of-life [27,28], and mood. [29-31] VASs are brief and simple for the user to answer. Moreover, it reduces the respondent burden to fill up long questionnaires. The visual analog scale will be incorporated into the app to assess the baseline and posttherapy stress and anxiety.

\section{Introductory Audio about the Self-help App}

An opening audio will address the following questions.

What is Mindfulness Meditation?

What is the importance of practicing Mindfulness?

How can it be practiced in the busy life?

What are the benefits of practicing Mindfulness?

How conventional psychotherapy incorporated into the Mindfulness App?

What are the benefits of using self-help App?

\section{Guided Self-help App Program for Stress}

The guided self-help program is designed on the basis of daily meditation. In this stress module, the app shall progressively add guidance through the techniques (Breathing followed by body scanning, observing thoughts, and visualization) along the 21 days. After completing the 21 days program, user can practise for 45 days to cultivate a habit to adapt the practice in daily life. (figure 3 )

\section{Breath Focused Attention}

Breathing technique is performed at the beginning of all the sessions. Changes in the emotions will affect the regular rhythm of the breathing. Shifting the focus to the breath, spontaneously regularizes the breathing and also calms down the mind. In this self-help program, two kinds of breathing will be practiced. The first step in breathing technique is the Deep Breathing. The user will be guided to breathe deeply, the air coming in through the nose entirely fills the lungs, and the lower belly rises, and then breathe out through the mouth. In the second step is Counting the Breath. After the outvbreath, count one, then breathe in and out and count two, and so on up to ten, and then start again at one. Both these breathing techniques will be performed in $2-3$ minutes.

\section{Body Scanning}

The most important proposed methods to reduce stress is relaxation, of which one of the most applicable techniques is Progressive Muscle Relaxation (PMR). Body scanning technique is based on PMR. PMR is a technique in which the individuals attain relaxation through active contraction of a group of specific muscles and then releasing them in a progressive manner and reach self-peace. After breathing technique, body scanning is practiced for 3-5 minutes.

\section{Observing Thoughts}

The nature of the mind create thoughts spontaneously. Although automatic thoughts are an element of both normal and abnormal cognitions, the presence of a consistent pattern of automatic negative thoughts leads to one's reduced ability to function and adequately adapt to the environment. [32] Observing thoughts is practiced after the body scanning for another 3-5 minute and it is based on cognitive behavioral therapy. 
The first step is identifying thoughts. The second step is to bring awareness to the thought without being judgmental. This practice, makes the mind identify the source of negative belief, challenges the thinking and sometimes consider the consequences of the negative belief. Moreover, being aware of the negative thinking will spontaneously lay alternative thinking patterns in the brain.

\section{Visualization Technique}

Visualization or imagery technique offers yet another avenue of stress reduction. This technique involves the systematic practice of creating a detailed mental image that relaxes the mind. It works by associating the sensations of relaxation with a peaceful visual image so that the future practice sessions involving imagery alone will quickly bring back to mind the physical sensation of relaxation.

\section{Anxiety Guided Meditation Program}

Anxiety is characterized by excessive, uncontrollable worry about a variety of topics that occurs more days than not for a period of at least six months. The worry causes distress and/or functional impairment, and is associated with at least three of the following features: restlessness or feeling keyed up or on edge, being easily fatigued, difficulty concentrating or having one's mind go blank, irritability, muscle tension, and sleep disturbance. [33]

The guided self-help program is designed on the basis of Mindfulness, CBT, and Positive Psychology. In this anxiety module, the app shall progressively add guidance through the techniques (Noting and Labeling unpleasant sensation and negative thoughts, and self-compassion meditation) along the 21 days. After completing the 21 days program, user can practise for 45 days to cultivate a habit to adapt the practice in daily life. (figure 3 )

\section{Breathing}

Like the stress guided meditation program, the anxiety guided meditation program also starts with the deep breathing and breath counting technique to calm the mind.

\section{Noting Unpleasant Physical Sensation}

A panic attack is a sudden surge of overwhelming fear, usually accompany by stressing physical symptoms. It comes without warning and often without any obvious reasons. Panic attacks can be managed by being aware of the physical sensations because it reduces the anxiety drastically. Noting is a traditional technique practiced in Buddhist meditation. To note something means to notice it and then focus on it intently, but gently for a few seconds, unless it happens to vanish immediately. In the anxiety program, the user will specifically notice the unpleasant physical sensations like, heart pounding, shivering, sweating, feeling cold, itching, etc. Intentionally focusing on the unpleasant physical sensations will spontaneously dissolve the panic attack.

\section{Labelling Unpleasant Physical Sensation}

After noticing the unpleasant physical sensation, labeling them using a name or a phrase in the mind.

\section{Noting Negative Thoughts and Emotions}

Emotion is a combination of physical sensations, thoughts, and urges. Emotions are complex, but they can be easily noticed. The user will be asked to notice the negative thoughts or emotions surfacing from 
the mind. This enables the user to bring the attention to the thoughts and makes them dive deep inside their mind. Intentionally focusing on negative thoughts will train the mind to do alternative thinking. Like, ' where does the thoughts come from?, does this thought bring benefit to me', etc.

\section{Labelling Negative Thoughts and Emotions}

No matter how complex the emotions could be, in the beginning, it will be difficult to label them. It is because people with anxiety will be less aware of their feelings, and less likely to figure out to regulate them. Thus, making an effort to label the emotions and negative thoughts in a nonjudgmental way can be a quite valuable psychological approach to regulating the emotions in a positive way.

\section{Self-compassion Meditation}

The perspective of positive psychology emphasizes a focus on strengths and resourcefulness or flourishing, rather than a focus on deficits and problems or floundering during the stage of adolescence. Flourishing has been described as encompassing factors that include positive emotion, engagement with what one is doing, a sense of accomplishment, and healthy relationships. [34] One positive factor that has been shown to be associated with well-being in adults is self-compassion. Welcoming negative emotions rather than resisting or suppressing them, self-compassionate behaviors are posited to engender positive emotions and are linked to psychological strengths. [35]

\section{Energizers}

Energizers are simple exercises that can be done within 1-5 minutes any time during the day, especially when the users are undergoing stressful events or going through anxiety. These energizers are created using psychological therapies such as positive psychology, alternative thinking, cognitive-behavioral therapy incorporated into a short guided meditation. It is the simple, powerful method to overcome stress and anxiety during work hours. The users can select one or two energizers during their work hours that spontaneously reduce their stress and anxiety. Some of the energizers in the app are as follows.

Progressive muscle relaxation- consciously creating tension in a specific part of the muscles and relaxes them.

Quieting the Mind- It is a visualization technique, where the user has to bring their attention to their favorite object and perform deep breathing. This brings spontaneous relaxation to the mind.

Refocusing- In this simple technique, the user has to notice five things that they hear and five things that they see.

Meeting Minutes- This short energizer can be done before the user goes to a meeting. It is called as 4-78 breath. The user has to breathe in through their nose for 4 seconds, hold it for 7 seconds, and breath out for 8 seconds. This exercise can be done for 4 or 5 times.

\section{Group Meditation}

A definite time will be fixed in mornings and evenings so that users can practice meditation together on the app. Many research studies have highlighted the importance of group meditation. A retrospective Study was conducted in twenty-four cities in the United States with populations over 10,000 with $1 \%$ or more of their population practicing the Transcendental Meditation program by 1972. These experimental cities were compared to twenty-four control cities, which were selected by an independent investigator before collection of the last several years of data. The study examined change in the FBI total crime index in 1973 , the year after the $1 \%$ cities reached $1 \%$ and studied the change in crime rate trend for six post- 
intervention years from 1972-1977. In 1973 there was a significant decrease in crime rate by $24 \%$ $(\mathrm{p}<.001)$ in $1 \%$ cities about controls. [36]

\section{Social Support}

Social support has been described as 'support accessible to an individual through social ties to other individuals, groups, and the larger community.' [37] Numerous studies indicate social support is essential for maintaining physical and psychological health. Social support may moderate genetic and environmental vulnerabilities and confer resilience to stress and anxiety, possibly via its effects on the hypothalamic-pituitary-adrenocortical (HPA) system, the noradrenergic system, and central oxytocin pathways. [38] Members who are using the self-help app can interact with all the members in the platform to exchange their thoughts, feelings, and emotions, providing each other mental support.

\section{Helping hands}

Psychological mentors help the users to cope with the stress and anxiety. Coping efforts may be directed outward toward changing the environment (problem-focused) or inward toward changing the meaning of the event (emotion-focused). In a quasi-experimental study. Sixty-six first year students (mentees) and sixty-six fourth-year students (mentors) were eligible to be in the mentoring program. Mentors and mentees contacted each other weekly, as required, to provide information and support. To determine the efficiency of the mentoring program, a Locus of Control Scale, the Ways of Coping Inventory and Mentoring Assessment Form were filled out by mentees. They found that the mentoring program increased students' internal locus of control and active coping with stress. The increase in internal locus of control showed parallelism with students' behaviors of seeking social support. [39] In this self-help platform, certified and experienced mentors will be helping the users to cope with stress and anxiety.

\section{Conclusion}

Self-help program incorporating psychotherapy and mindfulness is a promising way to resolve mild to moderate stress and anxiety. Even though the self-help app is designed on the basis of psychotherapy and mindfulness, extensive research needs to be done to scrutinize the effectiveness in reducing stress and anxiety. Therefore, future research is warranted to understand the benefits of the self-help app.

\section{Acknowledgment}

The author would like to thank the Uber Health Tech Pvt Ltd, Bangalore, India (https://www.zoojoo.be/) for funding this research. The funding body had no influence on the developing the module of the study. A special word of gratitude to Mrs. Shruthi Avinash, who has read and commented on the article.

\section{References}

1. Cox, T., Griffiths, A., \& Rial-González, E. (2000). Research on work-related stress. Luxembourg: Office for Official Publications of the European Communities.

2. Harnois, G., \& Gabriel P., (2000) Mental health and work: Impact, issues, and good practices. Mental Health Policy and Service Development Department of Mental Health and Substance Dependence Noncommunicable Diseases and Mental Health. World Health Organization. http://www.who.int/mental health/media/en/712.pdf. 
3. Vasudevan, M. (2003). Chapter-15 Emotional Stress, Emotional Problems, Mental Illness. Emotional Stress. Jaypee Brothers Medical Publishing. doi:10.5005/jp/books/10257_15.

4. Nich, R. P. (1998). The impact of training and support on stress among care staff in nursing and residential homes for the elderly. Journal of Mental Health, 7(1), 59-70. doi:10.1080/09638239818346.

5. Melchior, M. E., Philipsen, H., Abu-Saad, H. H., Halfens, R. J., Berg, A. A., \& Gassman, P. (1996). The effectiveness of primary nursing on burnout among psychiatric nurses in long-stay settings. J Adv Nurs Journal of Advanced Nursing, 24(4), 694-702. doi:10.1046/j.13652648.1996.02457.x

6. Kabat-Zinn J. (1990) Full Catastrophe Living: Using the Wisdom of your Body and Mind to Face Stress, Pain and Illness. New York: Dell Publishing.

7. Kabat-Zinn, J. (1982). An outpatient program in behavioral medicine for chronic pain patients based on the practice of mindfulness meditation: Theoretical considerations and preliminary results. General Hospital Psychiatry, 4(1), 33-47. doi:10.1016/0163-8343(82)90026-3.

8. Kabat-Zinn, J., Lipworth, L., \& Burney, R. (1985). The clinical use of mindfulness meditation for the self-regulation of chronic pain. J Behav Med Journal of Behavioral Medicine, 8(2), 163-190. doi:10.1007/bf00845519.

9. Bishop, S. R. (2002). What Do We Really Know About Mindfulness-Based Stress Reduction? Psychosomatic Medicine, 64(1), 71-83. doi:10.1097/00006842-200201000-00010.

10. Proulx, K. (2003). Integrating Mindfulness-Based Stress Reduction. Holistic Nursing Practice, 17(4), 201-208. doi:10.1097/00004650-200307000-00007

11. Praissman, S. (2008). Mindfulness-based stress reduction: A literature review and clinician's guide. Journal of the American Academy of Nurse Practitioners $J$ Amer Acad Nurse Practitioners, 20(4), 212-216. doi:10.1111/j.1745-7599.2008.00306.x.

12. Chiesa, A., \& Serretti, A. (2009). Mindfulness-Based Stress Reduction for Stress Management in Healthy People: A Review and Meta-Analysis. The Journal of Alternative and Complementary Medicine, 15(5), 593-600. doi:10.1089/acm.2008.0495.

13. Toneatto, T., \& Nguyen, L. (2007). Does mindfulness meditation improve anxiety and mood symptoms? A review of the controlled research. Can J Psychiatry, 52, 260-266.

14. Chiesa, A., \& Serretti, A. (2010). A systematic review of neurobiological and clinical features of mindfulness meditations. Psychol Med, 40, 1239-1252.

15. Hofmann, SG., Sawyer, AT., Witt, AA., \& Oh, D. (2010). The effect of mindfulness-based Therapy on anxiety and depression: a meta-analytic review. J Consult Clin Psychol, 78, 169-183.

16. Lueke, A., \& Gibson, B. (2014). Mindfulness Meditation Reduces Implicit Age and Race Bias. The role of reduced automaticity of Responding. Social Psychological \& Personality Science, 24, $1-8$.

17. Santarnecchi, E., D'Arista, S., Egiziano, E., Gardi, C., Petrosino, R., Vatti, G., Reda, M., \& Rossi, A. (2014). Interaction between neuroanatomical and psychological changes after mindfulnessbased training. PLOS ONE. 9(10), e108359.

18. Aikens, K.A., Astin, J., Pelletier, K.R., Levanovich, K., Baase, C.M., Park, Y.Y., \& Bodnar, C.M. (2014). Mindfulness goes to work: Impact of an online workplace intervention. Journal of Occupational and Environmental Medicine, 56(7), 721-731.

19. Webb, TL., Joseph, J., Yardley, L., \& Michie, S. (2010). Using the internet to promote health behavior change: a systematic review and meta-analysis of the impact of theoretical basis, use of behavior change techniques, and mode of delivery on efficacy. J Med Internet Res. 12, e4.

20. Allexandre, D., Bernstein, AM., Walker, E., Hunter, J., Roizen, MF., \& Morledge, TJ. (2016). A web-based Mindfulness Stress Management Program in a Corporate Call Center. A Randomized Clinical Trial to Evaluate the Added Benefit of Onsite Group Support. American College of Occupational and Environmental Medicine, 28, 254-264. 
21. Barak, A., Klein, B., \& Proudfoot, JG. (2009). Defining internet-supported therapeutic interventions. Ann Behav Med, 38, 4-17.

22. Newswire. (n.d.). Retrieved August 30, 2016, from http://www.nielsen.com/us/en/insights/news/2014/smartphones-so-many-apps--so-muchtime.html.

23. Lundgren, J. G., Dahlström, Ö., Andersson, G., Jaarsma, T., Köhler, A. K., \& Johansson, P. (2016). The Effect of Guided Web-Based Cognitive Behavioral Therapy on Patients With Depressive Symptoms and Heart Failure: A Pilot Randomized Controlled Trial. J Med Internet Res Journal of Medical Internet Research, 18(8). doi:10.2196/jmir.5556 .

24. Bruera, E., Kuehn, N., Miller, M. J., Selmser, P., \& Macmillan, K. (n.d.). Edmonton Symptom Assessment System. PsycTESTS Dataset. doi:10.1037/t07978-000.

25. Kremer, E., Atkinson, H. J., \& Ignelzi, R. J. (1981). Measurement of pain: Patient preference does not confound pain measurement. Pain, 10(2), 241-248. doi:10.1016/0304-3959(81)90199-8.

26. Scott, J., \& Huskisson, E. C. (1976). Graphic representation of pain. Pain, 2(2), 175-184. doi:10.1016/0304-3959(76)90113-5.

27. Boer, A. D., Lanschot, J. V., Stalmeier, P., Sandick, J. V., Hulscher, J., Haes, J. D., \& Sprangers, M. (2004). Is a single-item visual analogue scale as valid, reliable and responsive as multi-item scales in measuring quality of life? Qual Life Res Quality of Life Research, 13(2), 311-320. doi:10.1023/b:qure.0000018499.64574.

28. Hyland, M. E., \& Sodergren, S. C. (1996). Development of a new type of global quality of life scale, and comparison of performance and preference for 12 global scales. Qual Life Res Quality of Life Research, 5(5), 469-480. doi:10.1007/bf00540019

29. Lingjærde, O., \& Føreland, A. R. (1998). Direct assessment of improvement in winter depression with a visual analogue scale: High reliability and validity. Psychiatry Research, 81(3), 387-392. doi:10.1016/s0165-1781(98)00119-x.

30. Steiner, M., Streiner, D. L., Steinberg, S., Stewart, D., Carter, D., Berger, C., Grover, D. (1999). The measurement of premenstrual mood symptoms. Journal of Affective Disorders, 53(3), 269273. doi:10.1016/s0165-0327(98)00121-9.

31. Williams, V. S., Morlock, R. J., \& Feltner, D. (2010). Psychometric evaluation of a visual analog scale for the assessment of anxiety. Health and Quality of Life Outcomes, 8(1), 57. doi:10.1186/1477-7525-8-57.

32. Arpin-Cribbie, C. A., \& Cribbie, R. A. (2007). Psychological correlates of fatigue: Examining depression, perfectionism, and automatic negative thoughts. Personality and Individual Differences, 43(6), 1310-1320. doi:10.1016/j.paid.2007.03.020.

33. American Psychiatric Association. (2000). Diagnostic and statistical manual of mental disorders (4th-Text Revision ed.). Washington, DC.

34. Seligman, M. E., \& Csikszentmihalyi, M. (2000). Positive psychology: An introduction. American Psychologist, 55(1), 5-14. doi:10.1037//0003-066x.55.1.5.

35. Macbeth, A., \& Gumley, A. (2012). Exploring compassion: A meta-analysis of the association between self-compassion and psychopathology. Clinical Psychology Review, 32(6), 545-552. doi:10.1016/j.cpr.2012.06.003.

36. Dillbeck, M. C. (1990). Test of a field theory of consciousness and social change: Time series analysis of participation in the TM-Sidhi program and reduction of violent death in the U.S. Soc Indic Res Social Indicators Research, 22(4), 399-418. doi:10.1007/bf00303834.

37. Lin, N., Ensel, W. M., Simeone, R. S., \& Kuo, W. (1979). Social Support, Stressful Life Events, and Illness: A Model and an Empirical Test. Journal of Health and Social Behavior, 20(2), 108. doi:10.2307/2136433.

38. Ozbay, F., Fitterling, H., Charney, D., \& Southwick, S. (2008). Social support and resilience to stress across the life span: A neurobiologic framework. Current Psychiatry Reports Curr Psychiatry Rep, 10(4), 304-310. doi:10.1007/s11920-008-0049-7. 
39. Demir, S., Demir, S. G., Bulut, H., \& Hisar, F. (2014). Effect of Mentoring Program on Ways of Coping with Stress and Locus of Control for Nursing Students. Asian Nursing Research, 8(4), 254-260. doi:10.1016/j.anr.2014.10.004.

(Tables \& Figures)

Figure 1 Schematic Representation of the Root Causes and the Physical, Mental, and Emotional Manifestation of Stress and Anxiety

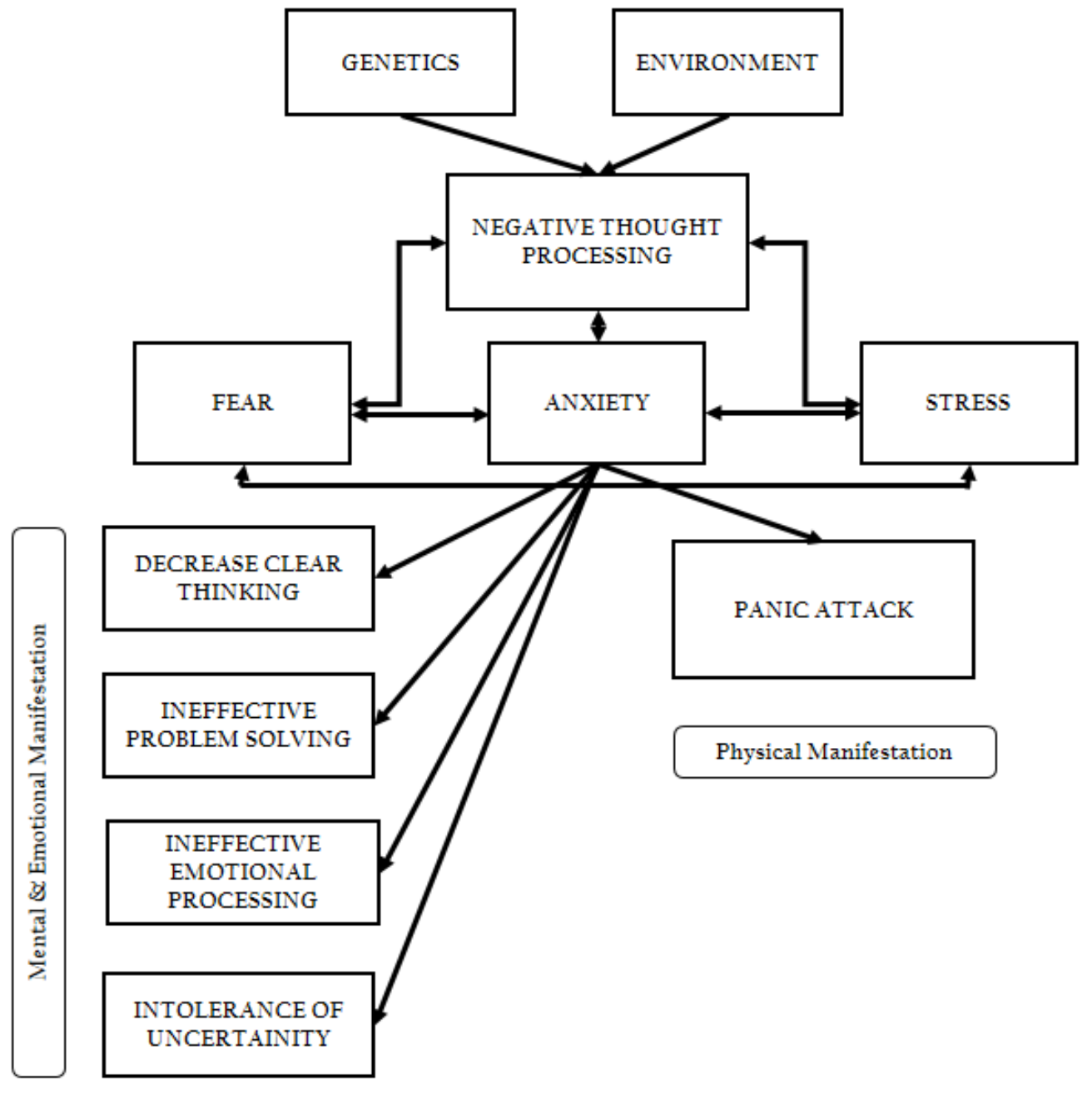


Figure 2 Aware Self-Help App Model

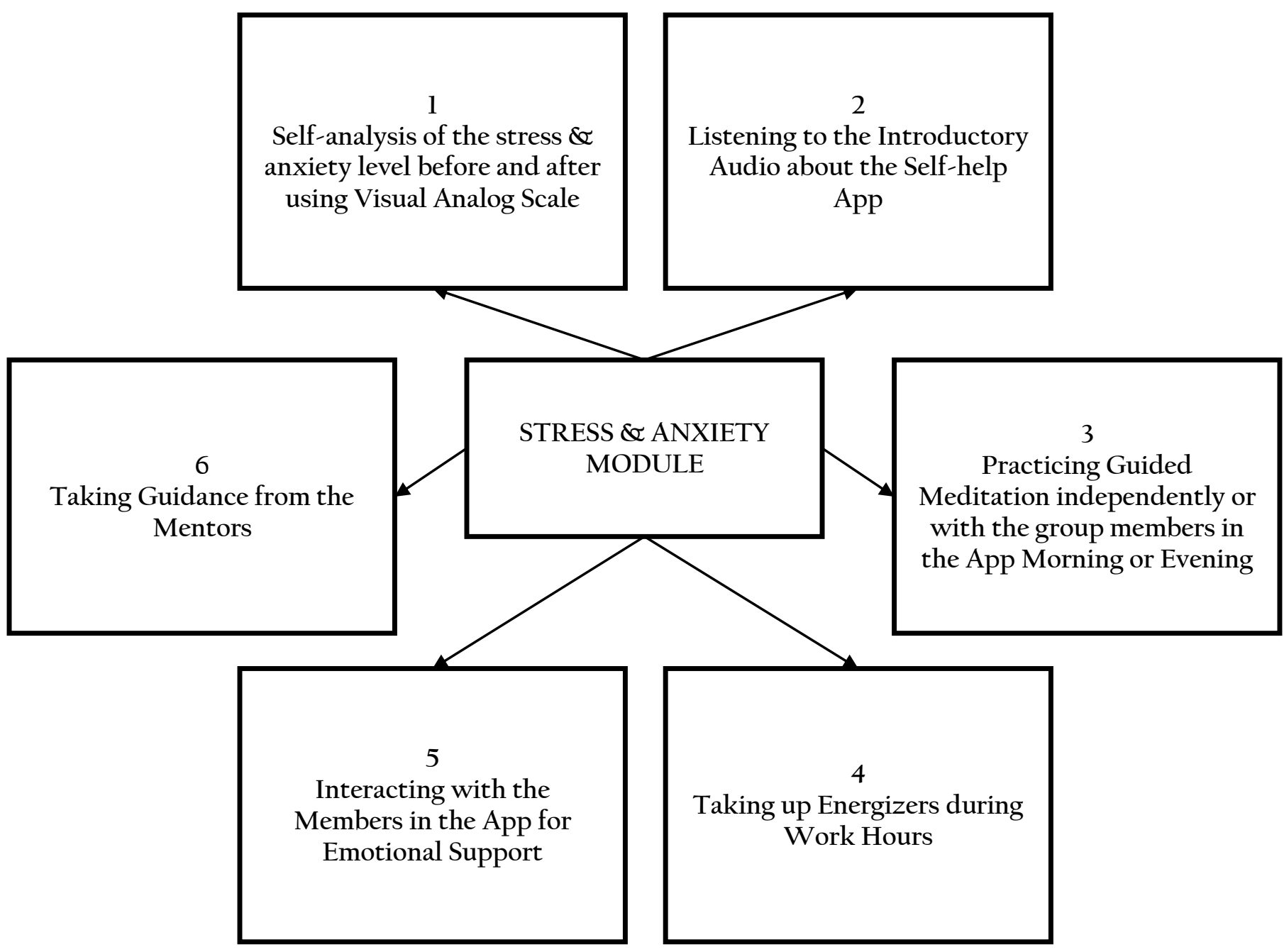


Figure 3 21-Days Guided Meditation Sessions for Stress and Anxiety
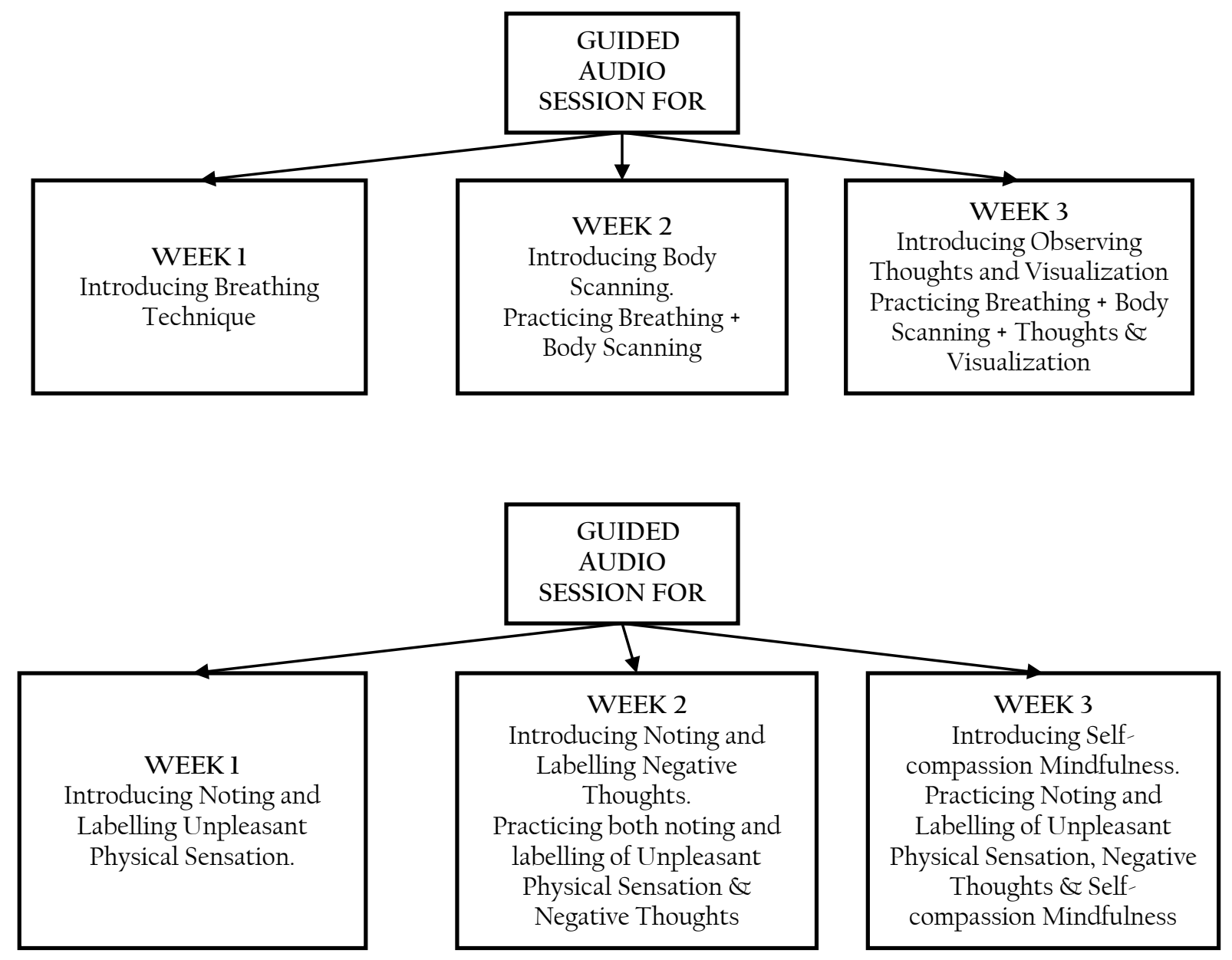